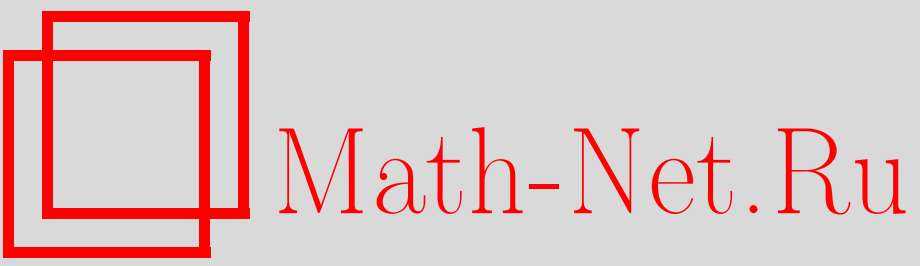

A. M. Zubkov, V. I. Kruglov, О квантилях минимальных весов кодовых слов в случайных линейных кодах над $\mathbf{F}_{p}$, Матем. вопр. криптогр., 2018, том 9, выпуск 2, 99-102

DOI: https://doi.org/10.4213/mvk258

Использование Общероссийского математического портала Math-Net.Ru подразумевает, что вы прочитали и согласны с пользовательским соглашением

http://www.mathnet.ru/rus/agreement

Параметры загрузки:

IP : 54.198 .187 .58

26 апреля 2023 г., $11: 47: 24$ 
МАТЕМАТИЧЕСКИЕ ВОПРОСЫ КРИПТОГРАФИИ

2018 T. 9 № 2 C. 99-102

УДК 519.719 .2

DOI https://doi.org/10.4213/mvk258

\section{On quantiles of minimal codeword weights of random linear codes over $\mathbf{F}_{p}$}

A. M. Zubkov, V. I. Kruglov

Steklov Mathematical Institute of Russian Academy of Sciences, Moscow

Получено 06.II.2017

Abstract. We propose explicit equations for two-sided estimates of quantiles of minimal non-zero codeword weight distributions for random equiprobable linear code with given dimension over the prime field $\mathbf{F}_{p}$. It is shown that the differences between quantiles of these distributions are bounded by values depending only on $p$ and levels of quantiles.

Key words: random linear codes, distributions of minimal codeword weights, quantile estimates

О квантилях минимальных весов кодовых слов в случайных линейных кодах над $\mathbf{F}_{p}$

\section{А. М. Зубков, В. И. Круглов}

Математический институт им. В. А. Стеклова РАН, Москва

Аннотация. Получены явные уравнения для двусторонних оценок квантилей распределений минимальных весов ненулевых кодовых слов в случайных равновероятных линейных кодах заданной размерности над простым полем $\mathbf{F}_{p}$. Показано, что разности между квантилями этих распределений ограничены величинами, зависящими только от $p$ и уровней квантилей.

Ключевые слова: случайные линейные коды, распределения минимальных весов кодовых слов, оценки квантилей

Citation: Mathematical Aspects of Cryptography, 2018, v. 9, № 2, pp. 99-102 (Russian)

(c) Академия криптографии Российской Федерации, 2018 г. 
Let $p$ be a prime number, $\mathbf{F}_{p}$ be a prime field, $\mathbf{F}_{p}^{N}=\left\{X=\left(x_{1}, \ldots, x_{N}\right)\right.$ : $\left.x_{1}, \ldots, x_{N} \in \mathbf{F}_{p}\right\}$ be $N$-dimensional linear space over $\mathbf{F}_{p}$. Any $k$-dimensional subspace $L \subset \mathbf{F}_{p}^{N}$ is $k$-dimensional linear code. Weight $w(X)=\sum_{k=1}^{N} I\left\{x_{k} \neq 0\right\}$ of the vector $X=\left(x_{1}, \ldots, x_{N}\right) \in \mathbf{F}_{p}^{N}$ is the number of its non-zero coordinates. Let $\mu_{*}(L)=\min \{w(X): X \in L \backslash\{0\}\}$ be the minimal weight of non-zero codewords in a linear code $L$.

The statement below is a direct consequence of results obtained in [7].

Theorem. If $L \subset \mathbf{F}_{p}^{N}$ is a random linear $k$-dimensional code in $\mathbf{F}_{p}^{N}$ having the uniform distribution on the set of all such codes, then

$$
\frac{1}{1+\frac{p-1}{\left(p^{k}-1\right) \Sigma_{N, p}^{1, s}}} \leqslant \mathbf{P}\left\{\mu_{*}(L) \leqslant s\right\} \leqslant p^{k} \Sigma_{N, p}^{1, s}, \quad \Sigma_{N, p}^{a, b} \stackrel{\text { def }}{=} \sum_{u=a}^{b} C_{N}^{u} \frac{(p-1)^{u}}{p^{N}} .
$$
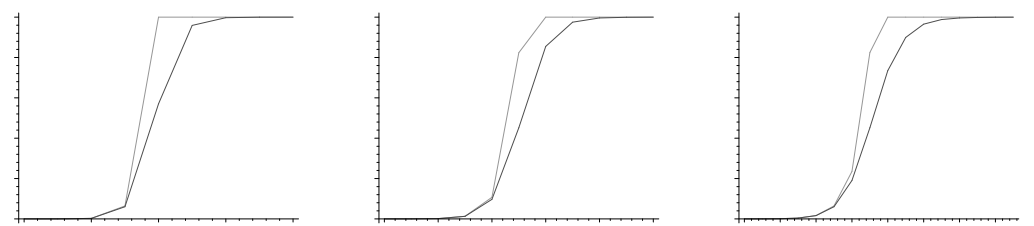

Fig 1. Two-sided bounds for $\mathbf{P}\left\{\mu_{*}(L) \leqslant s\right\}, N=128$, $\operatorname{dim} L=96,64,32$
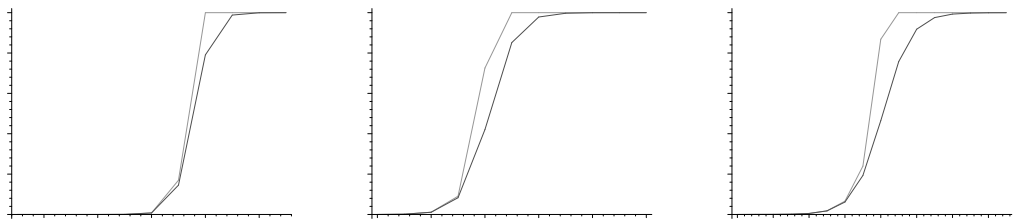

Fig 2. Two-sided bounds for $\mathbf{P}\left\{\mu_{*}(L) \leqslant s\right\}, N=1024, \operatorname{dim} L=768,512,256$

For the case $\mathbf{F}_{2}^{N}$ estimates (1) are illustrated graphically on Fig. 1 and Fig. 2 where the lower and upper bounds for probabilities $\mathbf{P}\left\{\mu_{*}(L) \leqslant s\right\}$ are presented correspondingly for $N=128, N=1024$ and several values of $\operatorname{dim} L$. Figures 1 and 2 show that distributions of $\mu_{*}(L)$ are highly concentrated. In what follows we propose an approach to estimate the quantiles of these distributions without calculating binomial sums.

It follows from [6] that if $\Phi(x)=(2 \pi)^{-1 / 2} \int_{-\infty}^{x} e^{-u^{2} / 2} d u$ and

then

$$
H(x, r)=x \ln \frac{x}{r}+(1-x) \ln \frac{1-x}{1-r},
$$

$$
\Phi\left(-\sqrt{2 N H\left(\frac{s}{N}, \frac{p-1}{p}\right)}\right)<\Sigma_{N, p}^{0, s}=\Sigma_{N, p}^{1, s}+\frac{1}{p^{N}}<\Phi\left(-\sqrt{2 N H\left(\frac{s+1}{N}, \frac{p-1}{p}\right)}\right) .
$$


Let us define values $z_{C}>0$ and $x_{C}<1-\frac{1}{p}$ as solutions of equations

$$
\Phi\left(-\sqrt{2 z_{C}}\right)=\frac{C}{p^{k}}, \quad N H\left(x_{C}, 1-\frac{1}{p}\right)=z_{C} .
$$

Then according to (2)

$$
p^{k}\left(\Sigma_{N, p}^{1,\left\lfloor N x_{C}\right\rfloor-1}+\frac{1}{p^{N}}\right)<C=p^{k} \Phi\left(-\sqrt{2 N H\left(x_{C}, \frac{p-1}{p}\right)}\right)<p^{k}\left(\Sigma_{N, p}^{1,\left\lceil N x_{C}\right\rceil}+\frac{1}{p^{N}}\right),
$$

where $\lceil x\rceil$ denotes the minimal integer in $[x, \infty)$ and $\lfloor x\rfloor$ denotes the maximal integer in $(-\infty, x]$. Combining these inequalities with (1) we find that

$$
\begin{gathered}
1-\frac{p-1}{C+p-1}=\frac{1}{1+\frac{p-1}{C}} \approx \frac{1}{1+\frac{p-1}{\left.\left(p^{k}-1\right) \Sigma_{N, p}^{1,\left\lceil N x_{C}\right.}\right\rceil}} \leqslant \mathbf{P}\left\{\mu_{*}(L) \leqslant\left\lceil N x_{C}\right\rceil\right\}, \\
\mathbf{P}\left\{\mu_{*}(L) \leqslant\left\lfloor N x_{C}\right\rfloor-1\right\} \leqslant p^{k} \Sigma_{N, p}^{1,\left\lfloor N x_{C}\right\rfloor-1}<C,
\end{gathered}
$$

the approximation in the left hand side of (5) is good if $p^{k}$ is large.

So, for small $\alpha$ the approximate value of $\alpha$-quantile of $\mu_{*}(L)$ distribution is $N x_{C}$ with $C=\alpha$ and the approximate value of $(1-\alpha)$-quantile is $N x_{C}$ with $C=(p-1) / \alpha$. For specific values of $p, N, k, C$ equations (3) may be solved numerically.

Approximate formula for the solution of equation $\Phi(-z)=q$ with the accuracy $|\varepsilon(q)|<0.003$ may be found in [1]:

$$
z(q)=t-\frac{2.30753+0.27061 t}{1+0.99229 t+0.04481 t^{2}}+\varepsilon(q), \quad t=\sqrt{\ln q^{-2}}, 0<q \leqslant \frac{1}{2} .
$$

Applying (7) to the first equation $\Phi\left(-\sqrt{2 z_{C}}\right)=\frac{C}{p^{k}}$ in (3) we find that

$$
z_{C} \approx \frac{1}{2}\left(t_{C}-\frac{2.30753+0.27061 t_{C}}{1+0.99229 t_{C}+0.04481 t_{C}^{2}}\right)^{2}, t_{C}=\sqrt{\ln \frac{p^{2 k}}{C^{2}}}=\sqrt{2(k \ln p-\ln C)} .
$$

If $\left|\ln C_{1}\right| \leqslant\left|\ln C_{2}\right| \leqslant \theta k \ln p$ for $\theta<1$, then

$$
\left|t_{C_{1}}-t_{C_{2}}\right|=\frac{\left|\ln \left(C_{1} / C_{2}\right)\right|}{t_{C_{1}}+t_{C_{2}}}
$$

and the order of difference $\left|z_{C_{1}}-z_{C_{2}}\right|$ is

$$
\left|t_{C_{1}}^{2}-t_{C_{2}}^{2}\right|=\left|\ln \frac{C_{1}}{C_{2}}\right|
$$


Therefore the order of difference $x_{C_{1}}-x_{C_{2}}$ of roots of equations

$$
H\left(x_{C_{i}}, 1-\frac{1}{p}\right)=\frac{1}{N} z_{C_{i}}, \quad i=1,2,
$$

from (3) is $N^{-1}\left|\ln \left(C_{1} / C_{2}\right)\right|$. Further, the difference between $(1-\alpha)$ - and $\alpha$-quantiles $N x_{(p-1) / \alpha}$ and $N x_{\alpha}$ of $\mu_{*}(L)$ distribution has the order $\left|\ln \frac{\alpha^{2}}{p-1}\right|$. This crude estimates supports the validity of observation on the high concentration of $\mu_{*}(L)$ distribution near the value $N x_{1 / 2}$. If $N, k, N-k \rightarrow \infty$ then $x_{1 / 2}$ may be approximated by the root of equation

$$
H\left(x_{1 / 2}, \frac{p-1}{p}\right)=\frac{k \ln p}{N}
$$

this corresponds to the results of [3].

The case of maximal codeword weight of random linear $k$-dimensional code may be considered analogously.

The estimates of the minimal weights of nonzero codewords may be used to choose the parameters of McEliece cryptosystem [5]. If McEliece cryptosystem is used and someone has intercepted single encrypted message, he faces the problem of decoding of seemingly random linear code, such a problem is equivalent ([3], p. 368) to a problem of finding codeword of minimal weight in extended code with dimension increased by 1 . It was shown in [2] that general problem of determining minimal weight of codeword for given code is $N P$-hard.

\section{References}

[1] Handbook of Mathematical Functions, Tenth Printing, eds M. Abramowitz, I. A. Stegun: National Bureau of Standards, 1972, xiv $+1046 \mathrm{pp}$.

[2] Berlekamp E. R., McEliece R. J., van Tilborg H. C. A., "On the inherent intractability of certain coding problems", IEEE Trans. Inf. Theory, 24 (1978), 384-386.

[3] Canteaut A., ChabaudF., "A new algorithm for finding minimum-weight words in a linear code: application to McEliece's cryptosystem and to narrow-sense BCH codes of length 511", IEEE Trans. Inf. Theory, $44: 1$ (1988), 367-378.

[4] Feller W., An Introduction to Probability Theory and Its Applications, 3rd ed., 1, N. Y. etc.: J. Wiley \& Sons, 1970.

[5] McEliece R. J., A public-key cryptosystem based on algebraic coding theory., Jet Propulsion Lab. DSN Progress Report 42-44, 1978, http://ipnpr.jpl.nasa.gov/progress_report2/4244/44N.PDF.

[6] Zubkov A. M., Serov A. A., "A complete proof of universal inequalities for distribution function of binomial law", Theory Probab. Appl., $57: 3$ (2012), 597-602.

[7] Zubkov A. M., Kruglov V. I., "Statistical characteristics of weight spectra of random linear codes over GF(p).”, Matem. Voprosy Kriptogr., 5:1 (2014), 27-38 (in Russian). 